\title{
ELUM: o aplicativo de comunicação pública para indicadores culturais municipais
}

ELUM: the public communication's app for municipal cultural indicators

ELUM: la aplicación de comunicación pública para indicadores culturales municipales

\section{Tiago Costa Martins}

Doutor em Desenvolvimento Regional (Universidade de Santa Cruz do Sul). Professor dos programas de pósgraduação em Políticas Públicas (Universidade Federal do Pampa) e em Patrimônio Cultural (Universidade Federal de Santa Maria). Investigador colaborador no Centro de Investigação Transdisciplinar Cultura, Espaço e Memória - CITCEM, Universidade do Porto, Portugal. tiagomartins@unipampa.edu.br

0000-0003-0927-7148

\section{Claiton Marques Correa}

Doutorando em Ciência da Computação (Pontifícia Universidade Católica, RS). Professor no bacharelado em Sistemas de Informação (Instituto Federal Farroupilha). claiton.correa@iffarroupilha.edu.br.

\section{0-0003-2339-1844}

\section{Fernando Luis Oliveira}

Doutorando em Ciência da Computação (Universidade Federal de Pelotas, RS). Professor no bacharelado em Sistemas de Informação (Instituto Federal Farroupilha). fernando.oliveira@iffarroupilha.edu.br.

0000-0002-9158-8879

\section{Ícaro Lins Iglesias}

Mestre em Educação (Instituto Politécnico do Porto/Portugal). Professor no bacharelado em Sistemas de Informação (Instituto Federal Farroupilha). icaro.iglesias@iffarroupilha.edu.br.

\section{0-0002-9236-3102}

Correspondência: Universidade Federal do Tocantins, Reitoria, DIRETORIA DE COMUNICAÇÃO. Quadra 109
Norte Avenida NS 15, Plano Diretor Norte, 77001090 Palmas, TO - Brasil.

Recebido em: 16.02.2021.

Aceito em: 16.04.2021.

Publicado em: 01.07.2021.

\section{RESUMO:}

Este artigo apresenta o resultado da pesquisa sobre a articulação entre indicadores, políticas culturais, comunicação pública e a alocação dos recursos realizada pelas administrações públicas municipais no Rio Grande do Sul (Brasil). No estudo, a visão de uma ciência propositiva associa-se aos recursos tecnológicos que criam algoritmos e modelam aplicações com diversas funcionalidades. Desenvolveu-se um algoritmo associado a um software: o Elum. Relata-se, assim, a trajetória da pesquisa em que os dados acessados foram tratados (enquanto indicadores) e comunicados (enquanto comunicação pública) na busca por gerar uma equivalência cognitiva entre quem os dispõe e quem tem potencial interesse em compreendê-los.

PALAVRAS-CHAVES: Sistemas de informação; Política cultural; Administração pública.

\section{Introdução}

Apresenta-se, neste artigo, o resultado da pesquisa sobre a articulação entre indicadores, políticas culturais e comunicação pública no contexto das ações relacionadas à alocação dos recursos realizada pela administração pública municipal no Rio Grande do Sul. Sabe-se que agentes e instituições entram em relação com a realidade territorial e assumem responsabilidades no desenvolvimento das políticas culturais. $O$ caso da administração pública municipal, governo municipal, é um exemplo de uma agente protagonista no fomento/organização/estruturação da cultura nos municípios.

O protagonismo das prefeituras recai na alocação dos recursos públicos enquanto política pública alocativa. Recursos aplicados à cultura que, evidentemente, são de 
interesse público. Em tempos atuais fala-se, então, em transparência, accountability e controle social, estabelecidos por dispositivos legais e traduzidos em portais de acesso à informação, portais de transparência e controle social.

O "Controle Social" do Tribunal de Contas do Rio Grande do Sul é um exemplo de portal que fornece dados primários dos gastos municipais, dentre eles os de cultura. São dados dos 497 municípios do Rio Grande do Sul, em um banco de livre acesso à população, mas é pouco utilizado pelo modo com que apresenta as informações.

A transformação dos dados do ente público em conhecimento plausível de interpretação para os cidadãos passou a ser o ponto de interesse. Para tanto, a comunicação pública se estabeleceu no presente debate: através da comunicação é possível diminuir "o descompasso cognitivo" (MATOS, 2009). Destarte, objetivamente, a pesquisa criou um conjunto de indicadores culturais municipais a partir das informações disponíveis no Tribunal de Contas do Rio Grande do Sul sobre as despesas públicas. A comunicação pública foi contextualizada diante de algoritmos, interfaces e dispositivos que passaram a reordenar determinados fenômenos (LEMOS, 2020), principalmente aqueles ligados aos indivíduos no exercício do controle social das políticas públicas (SILVA, 2002). Esse movimento permitiu a operacionalização de um instrumento de informação para a comunicação pública com a criação de um sistema sociotécnico de indicadores por meio de um algoritmo constituído para tratar dados das despesas públicas das prefeituras do Estado do Rio Grande do Sul. Assim, o presente artigo procura relatar o desenvolvimento de um artefato de comunicação pública através de um software experimental.

\section{Indicadores para a comunicação pública, comunicação pública para os indicadores}

A relação entre indicadores e comunicação foi articulada desde 1980 com a International Conference on Communication, México. O encontro de intelectuais da área de comunicação marcou uma preocupação em debater o "futuro das sociedades desenvolvidas". Já com a atuação de George Gerbner (1919-2005), os indicadores são novamente utilizados como um instrumento capaz de ler determinada realidade: análise do conteúdo dramático da televisão e de seus efeitos sobre os espectadores.

O contexto que se coloca aqui é perceber os indicadores culturais como um mecanismo, um meio para alguma finalidade. Portanto, indicador não é um fim em si, mas é uma solução numérica que funciona como mecanismo-meio para a consecução de determinado objetivo.

Então, ao se se reconhecer que "as soluções numéricas para os assuntos políticos e sociais parecem estar em toda a parte e não podem deixar de ter alguma influência na 
conduta da vida pública" (REDDEN, 2015, p. 27) ${ }^{1}$, os indicadores para a comunicação pública são reconhecidos como uma solução numérica que auxilia o entendimento do que está em jogo neste interesse.

Sabe-se que os indicadores culturais foram aplicados sempre com mais intensidade para compreender a realidade cultural do Estado, da economia e da sociedade, mas, raramente, para articular essa realidade e apresentá-la à sociedade. Somente com os movimentos políticos e científicos da "cultura e governança" e "cultura e democracia" houve um reconhecimento em proporcionar um input da sociedade sobre o "comportamento" do Estado, por exemplo (MARTINS e PINTO, 2019).

Assim, as "entradas" na sociedade podem ser analisadas com os indicadores que servem para potencialmente dotar o cidadão de um dispositivo de interpretação do que "está ocorrendo" na realidade cultural, especialmente pela ascendência de atores da sociedade civil (e não da sociedade política) e da reconfiguração dos governos nos processos democráticos. Nessa ordem, fala-se em indicadores como mecanismo de governança e comunicação (DUXBURY, 2005) ou como ferramenta de diálogo político (FUKUDA-PARR, 2000).

Por outro lado, a comunicação pública deve criar fluxos de relações comunicativas na busca por uma equivalência cognitiva para que o interesse público transite numa esfera de diálogo entre governo e sociedade. O desempenho operativo da comunicação pública remete a uma ação estratégica, propositiva à produção de diálogo através dos indicadores. Reafirma-se, assim, que tal comunicação está num contexto mais amplo de democratização do saber para reduzir "o descompasso cognitivo" (MATOS, 2009).

Destarte, os princípios reconhecidos e aplicados pela comunicação pública dotam os indicadores de "envolvimento", enquanto "uma diretriz para uma agenda proativa e interativa com a sociedade, buscando engajamento e participação" (MARTINS e PINTO, 2019, p. 34). Busca-se, então, que o que é válido e reconhecido como informação e conhecimento para a administração pública seja igualmente aos cidadãos.

\section{Como foi estruturado o aplicativo}

O Elum é um artefato sociotécnico desenvolvido experimentalmente como um instrumento de informação para a comunicação pública². Trata-se de um aplicativo que

\footnotetext{
${ }^{1}$ Tradução livre para: "[...] numeric solutions to political and social affairs seem to be everywhere, and they cannot but have some influence on the conduct of public life".

2 O nome Elum surge da ligação das palavras "elo" e "um". O nome é uma homenagem às bandas de rock da cidade de Santa Maria, RS, que criaram um cenário independente para divulgação de sua arte com a produção, nos anos 90, de um compact disc (CD) intitulado "Elo Um". A ideia de
} 
procura criar um sistema de informação estruturada através da transformação de dados em indicadores para permitir a equivalência cognitiva entre a prestação de contas pública, emitida pelo governo municipal, e a leitura e compreensão pelo cidadão.

O Tribunal de Contas do Estado do Rio Grande do Sul (TCE) disponibiliza as despesas orçamentárias por empenhos, as quais contêm informações relativas às despesas orçamentárias dos Poderes e/ou Órgãos da esfera municipal, regidos pela Lei Federal $n^{\circ} 4320 / 64$. De forma geral, tais dados estão abertos para acesso de qualquer pessoa através do link http://dados.tce.rs.gov.br.

Entretanto, certas informações não são passíveis de leitura ou interpretação, seja pela sua complexidade ou pelo seu volume. Em termos práticos, o TCE disponibiliza seus dados em arquivos no formato CSV (Comma Separated Values), formato de arquivo de texto que pode ser usado para trocar dados de uma planilha entre aplicativos. Tais arquivos possuem milhares ou até milhões de registros, o que exige um computador com alto desempenho para visualizar seu conteúdo. Destaca-se que mesmo conseguindo visualizar as informações, dificilmente alguma pessoa poderia interpretálas ou ainda extrair algum conhecimento.

Nesse sentido, com o intuito de facilitar e viabilizar o acesso real à informação, e diante da carência de soluções adequadas para este fim, foi planejado o sistema Elum.

O processo de desenvolvimento do software foi dividido em quatro fases: a) Extração e transformação dos dados; b) Construção de um banco de dados; c) Construção de um sistema para internet; d) operacionalização da comunicação pública.

Extração e transformação: os dados presentes no arquivo fornecido pelo TCE são alimentados pelas prefeituras do estado do Rio Grande do Sul (RS), e não existe um padrão na maneira de inserir as informações. Geralmente, cada prefeitura possui um sistema próprio de gestão ou uma política de organização, o que implica diretamente na maneira de os dados serem reportados. Comumente, se utilizam siglas, abreviações ou códigos para descrever os empenhos.

Nesse sentido, foi necessário um mecanismo para extrair e analisar cada registro, de modo a padronizar a entrada dos dados, todavia, sem descaracterizar ou modificar a informação original. Por exemplo, o credor associado ao empenho pode ser uma pessoa física ou jurídica. Quando o Cadastro de Pessoa Física (CPF) ou Cadastro Nacional de Pessoa Jurídica (CNPJ) inicia com zero, em algumas prefeituras essa informação é removida, em razão de que o CPF/CNPJ é tratado como um número inteiro, logo, o zero

primeiro elo de uma cadeia é aqui associada por se entender que o investimento de uma prefeitura é o primeiro elo de uma cadeia de valor à cultura. 
à esquerda não tem valor e, em consequência, é subtraído. Assim sendo, requer um tratamento para padronizar e recompor a informação original.

Banco de dados: vencida a fase de extração foi necessário armazenar os dados coletados em algum local. Portanto, para organizar e possibilitar o acesso às informações um banco de dados foi criado.

Sistema: essa fase contemplou o desenvolvimento de um software que manipula as informações contidas no banco de dados. Trata-se de uma ferramenta que permite manejar as informações, fazer consultas e gerar relatórios.

Para construção do software proposto adotou-se a linguagem de programação Java, pois, segundo Mendes (2010), esta ferramenta é mais do que uma linguagem, é uma plataforma de desenvolvimento que tem a vantagem da compatibilidade com vários sistemas operacionais: Windows, Mac OS, Linux, entre outros.

Operacionalização da comunicação pública: essa etapa caracterizou-se pela operacionalização da comunicação através do uso estratégico de recursos que permitam realizar a propriedade de "comunicabilidade" e o efeito "comunicável" aos indicadores culturais.

\section{O processo de importação}

O TCE disponibiliza, anualmente, as prestações de contas dos municípios. Geralmente, em meados de abril é publicado um arquivo, no formato CSV, contendo uma média de 19 milhões de registros. Cada linha do documento contém 36 dados que são separados por vírgula e descrevem o empenho, por exemplo, data do lançamento, CPF/CNPJ do credor, valores pagos, empenhados e liquidados, função contábil, entre outros.

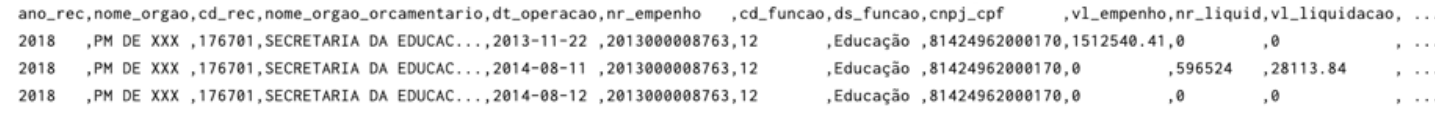

Figura 1: Amostra resumida do arquivo CSV.

Fonte: Martins et al. (2021).

A Figura 1 apresenta um exemplo resumido do formato do arquivo CSV, havendo, na primeira linha, doze termos separados por vírgula. Tais valores representam os 
cabeçalhos do documento, os quais são indicadores da origem de cada dado ${ }^{3}$. A Tabela 1 discrimina os dados reais dos arquivos já processados e que foram importadas para o Elum. Destaca-se que a divulgação sempre conta com um período de defasagem, ou seja, no ano corrente analisam-se os dados do ano anterior. Salienta-se que os dados referentes ao período de 2017 a 2019 passam de 61 milhões de linhas avaliadas e processadas.

\begin{tabular}{c|c|r|r}
\hline Ano Referência & Data publicação & Total de registros & Tamanho do arquivo (MB) \\
\hline 2017 & $26 / 04 / 2018$ & 19.494 .446 & 905,5 \\
\hline 2018 & $24 / 04 / 2019$ & 20.468 .603 & 967,6 \\
\hline 2019 & $24 / 04 / 2020$ & 21.377 .770 & 1070,3 \\
\hline
\end{tabular}

Tabela 1: Dados dos arquivos, publicados pelo TCE, já processados. Fonte: Martins et al. (2021).

\section{Importação de credor}

Um desafio no processo de importação foi a identificação do credor. O arquivo CSV continha uma única coluna para representar tal informação, e, em certos casos, não era possível identificar se era uma pessoa física ou jurídica, pois o algarismo presente naquela coluna não correspondia a um CPF ou CNPJ.

Acredita-se que este problema ocorria em virtude de que, em algum momento do processamento pelo TCE ou nos sistemas privados das prefeituras, essa informação era tratada como um número inteiro, logo, os códigos de CPF ou CNPJ que iniciavam com zero perdiam seus dados iniciais, descaracterizando seu formato base. Partindo-se do pressuposto de que o CPF e o CNPJ contêm 11 e 14 dígitos, respectivamente, desenvolveu-se um algoritmo que analisa o código, de modo a colocar zeros à esquerda até atingir a quantidade de dígitos de cada categoria. Após isso, verifica-se se é um CPF ou CNPJ válido. Em certos casos, as avaliações podem apontar como não identificado, entretanto, esses valores não representam um valor significativo. A Tabela 2 demonstra os valores coletados e categorizados por ano.

\begin{tabular}{l|r|r|r|r}
\hline Ano & CPFs válidos & CNPJs válidos & Não identificados (\%) & Total de registros \\
& $(\%)$ & $(\%)$ & & \\
\hline
\end{tabular}

\footnotetext{
${ }^{3}$ Salienta-se que, nessa imagem, para fins demonstrativos, as informações foram tratadas para que todos os conteúdos ficassem com o mesmo número de caracteres, visando facilitar a visualização dos dados, isto é, como se estivessem em colunas. O intuito é mostrar o modo com que os dados são disponibilizados para a comunidade.
} 


\begin{tabular}{l|r|r|r|c}
\hline 2017 & $168410(60,76)$ & $107656(38,84)$ & $1127(0,41)$ & 277.193 \\
\hline 2018 & $78860(73,99)$ & $27575(25,87)$ & $149(0,14)$ & 106.584 \\
\hline 2019 & $70634(74,5)$ & $24690(25,88)$ & $60(0,06)$ & 95.384 \\
\hline Total & $317904(66,35)$ & $159921(33,38)$ & $1336(0,28)$ & 479161 \\
\hline
\end{tabular}

Tabela 2: Total de credores analisados por ano.

Fonte: Martins et al. (2021).

Observa-se que na Tabela 2 existe um número expressivo de registros associados ao ano de 2017 quando comparados aos demais anos. Esse volume se deve ao fato de que todos os credores foram avaliados naquele ano, pois, foi o primeiro processo de tratamento de dados realizado. Nos anos subsequentes foram analisados apenas os novos credores, assim, um credor incluído em 2017 não foi analisado em 2018, e os inseridos em 2018 não foram analisados em 2019.

Para um pequeno percentual de credores $(0,28 \%)$ não foi possível determinar se era pessoa jurídica ou física. Essa limitação ocorreu porque algumas prefeituras utilizavam códigos personalizados para identificar seus credores. Tais códigos não seguiam um padrão ou uma convenção, sendo definidos e utilizados de forma livre pelos municípios.

Para identificar se um registro já havia sido processado ou não, utilizou-se como base o código do CPF ou CNPJ informado no arquivo de importação. Portanto, para cada linha do arquivo extraía-se o valor da coluna "cnpj_cpf" e se verificava se o código existia no banco de dados, caso não existisse ele era inserido. Para complementar os dados do credor adicionado, utilizou-se o teor da coluna "mm_credor" como descrição (nome/razão social).

Embora essa estratégia seja funcional e atenda o processo de importação de forma satisfatória, ela possui um efeito colateral. Nessa dinâmica, os códigos que não sejam CPFs ou CNPJs válidos podem se repetir. A repetição significa que não se tem uma descrição fidedigna do credor, por exemplo, supõe-se que o código 00000000000 seja utilizado pelo município $A$, o qual associa este código à descrição "Conselheiros tutelares". Quando este código for processado ele será incluído no banco de dados utilizando as informações adotadas pelo município A, porém, será classificado como "Não identificado". Nesse sentido, se um segundo município utilizar o mesmo código para descrever um credor diferente, o processo em pauta considera que o credor, embora seja diferente, já foi incluído e, eventualmente, poderá apresentar a descrição equivocada em alguns locais. 


\section{Banco de dados}

A abordagem de persistência adotada foi a relacional. Nessa proposta, os dados são armazenados em tabelas que se relacionam entre si. O sistema gerenciador de banco de dados utilizado nessa proposta foi o PostgreSQL.

O PostgreSQL é um sistema gratuito de código fonte aberto, que implementa um modelo de persistência objeto-relacional. Essa ferramenta consegue atender, de modo satisfatório, o banco de dados com altos volumes de informação e possui excelente desempenho (OBE e HSU, 2017).

O projeto de banco de dados para o sistema Elum compreende um total de 19 tabelas. Na Figura 2 apresenta-se o diagrama entidade-relacionamento (DER) proposto, com base na estrutura do arquivo CSV.

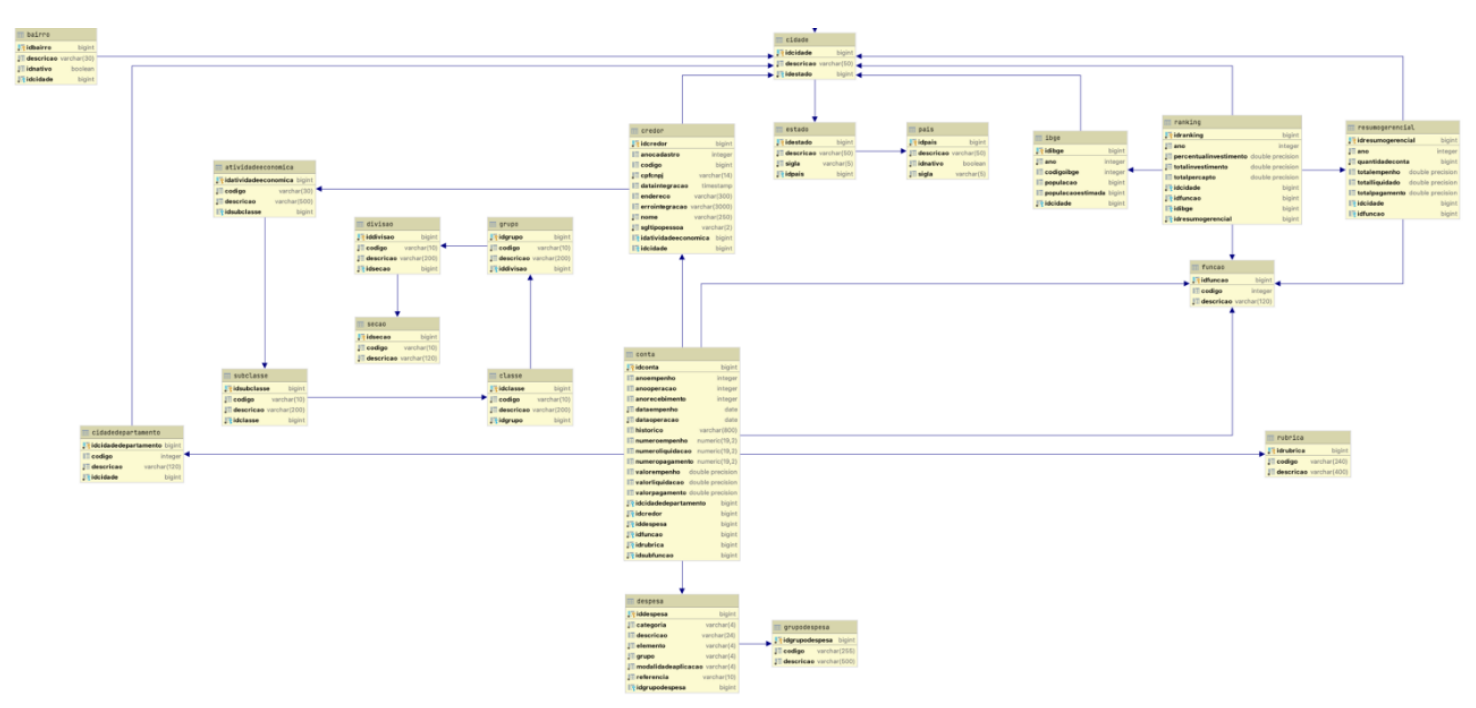

Figura 2: Diagrama entidade relacionamento Elum.

Fonte: Martins et al. (2021).

Na Figura 2 - diagrama entidade-relacionamento do banco de dados proposto - cada linha analisada no processo de importação do arquivo CSV terá seu conteúdo distribuído entre as tabelas, evitando repetições (redundância) e mantendo a integridade dos dados. Além dessas tabelas, há outras tabelas que fazem parte deste banco, contudo, elas foram suprimidas do diagrama porque dão suporte às funções básicas do sistema, por exemplo, históricos, controle de acesso, perfil de usuário, entre outras. O Quadro 1 apresenta um panorama do quantitativo de registros contidos no banco de dados.

\begin{tabular}{|l|l|r|}
\hline Tabela & Descrição & Total de registros \\
\hline Credor & $\begin{array}{l}\text { Armazena os dados dos credores das } \\
\text { prefeituras. }\end{array}$ & 479.161 \\
\hline
\end{tabular}




\begin{tabular}{|c|c|c|}
\hline Função & $\begin{array}{l}\text { A função contábil atribuída pela prefeitura } \\
\text { para o ordenamento das despesas }\end{array}$ & 175 \\
\hline Cidade & $\begin{array}{l}\text { Dados referentes ao município do estado do } \\
\text { RS e dos municípios associados aos credores } \\
\text { que são pessoas jurídicas }\end{array}$ & 1383 \\
\hline Cidade Departamento & $\begin{array}{l}\text { Refere-se ao departamento ou órgão dentro } \\
\text { do munícipio vinculado ao empenho. }\end{array}$ & 1.129 \\
\hline Resumo Gerencial & $\begin{array}{l}\text { Armazena os valores somados e agrupados } \\
\text { por município e ano, utilizado para fins de } \\
\text { resumos, estatísticas e classificações. }\end{array}$ & 1.497 \\
\hline IBGE & $\begin{array}{l}\text { Mantem os dados de estimativa populacional } \\
\text { para cada município por ano. Essas } \\
\text { informações são providas pelo Instituto } \\
\text { Brasileiro de Geografia e Estatística. }\end{array}$ & 1.491 \\
\hline Ranking & $\begin{array}{l}\text { Tabela utilizada para criar agrupamentos de } \\
\text { classificação, conforme indicadores. }\end{array}$ & 2.994 \\
\hline Despesa & Despesa associada ao empenho. & 283 \\
\hline Grupo Despesa & $\begin{array}{l}\text { Classificação própria para agrupar as } \\
\text { despesas. }\end{array}$ & 14 \\
\hline Conta & $\begin{array}{l}\text { Registra os empenhos que cada município } \\
\text { declarou junto ao TCE. }\end{array}$ & 61.340 .819 \\
\hline Rubrica & & 10.670 \\
\hline Estado & Unidade Federativa & 27 \\
\hline Pais & & 1 \\
\hline Atividade Econômica & & 1.089 \\
\hline Subclasse & & 1.334 \\
\hline Classe & & 681 \\
\hline Grupo & & 285 \\
\hline Divisão & & 87 \\
\hline Seção & & 21 \\
\hline
\end{tabular}

Quadro 1: Descrição das tabelas e quantidade de registros.

Fonte: Martins et al. (2021).

\section{Como foi desenvolvimento o aplicativo}

O software foi idealizado para ser acessado através de um navegador de internet, portanto, implica na adoção de um modelo conhecido como cliente servidor. Nessa abordagem, os utilizadores do sistema são conhecidos como clientes e acessam as aplicações que são processadas remotamente, isto é, um computador (servidor) é responsável por receber os pedidos (requisições) dos clientes, processá-las e retornar as respostas.

Nessa perspectiva, a ferramenta possui duas segmentações: a parte executada no cliente foi desenvolvida utilizando-se as tecnologias HTML, CSS e JavaScript; e a outra, a segmentação servidor, foi programada através da linguagem de programação Java. 


\section{Segmento cliente}

A parte cliente corresponde ao conteúdo que os usuários visualizam e com o qual interagem. Essa parte representa as interfaces (telas) que possibilitam a transmissão do conteúdo e a efetiva comunicação. Essa área exige planejamento e estudo para construir telas intuitivas que possibilitem que as pessoas consigam utilizar naturalmente a aplicação. Segundo Krug (2006), inúmeros aspectos influenciam a construção e a elaboração dos sistemas, que vão desde a disposição dos elementos, cores, linguagens, tamanhos, imagens entre outros. Nesse sentido, técnicas de Interface HumanoComputador (IHC) foram aplicadas a fim de tornar a aplicação simples e amigável, abstraindo a complexidade e a preocupação de entender como o sistema funciona, e conduzindo as pessoas de forma natural para as próximas etapas.

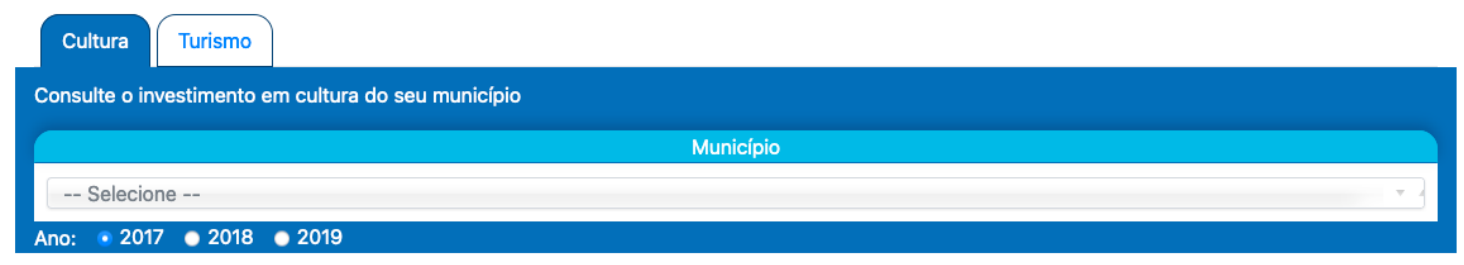

(B) Por favor, selecione uma cidade para visualizar os indicadores.

Figura 3: Proposta de interface inicial.

Fonte: Martins et al. (2021).

A Figura 3 apresenta a proposta de interface inicial da aplicação. Nessa aba, o visitante pode optar por visualizar os dados associados à Cultura (opção padrão) ou ao Turismo. Indiferente à modalidade escolhida, é necessário selecionar uma cidade e o ano de referência. Em termos práticos, Cultura e o ano 2017 já estão previamente selecionados, cabendo ao visitante selecionar uma cidade.

\section{Segmento servidor}

O servidor é responsável por realizar os procedimentos e tratamentos necessários para gerar os indicadores, ou seja, consultas ao banco de dados, agrupar informações, calcular e classificar resultados. Na prática, no servidor são construídas as regras de negócio, isto é, a lógica da aplicação. E para construí-las adotaram-se alguns padrões de projeto de software. MVC (Model, View, Controller), DAO (Data Access Object), Factory, Decorator, Facade entre outros. Quanto a bibliotecas de terceiros utilizou-se os frameworks Hibernate, Tiles, Log4j, Vraptor, Apache Commons, entre outros. 
No que diz respeito às ferramentas utilizadas, adotou-se o programa eclipse como ambiente de desenvolvimento, e o Apache Tomcat como ambiente de execução, além do Git, como estratégia para versar os códigos da aplicação.

A concepção arquitetural da aplicação levou em conta um minucioso planejamento, com o intuito de garantir que a aplicação possa evoluir e ser mantida de forma simples, mas, sobretudo, que outras pessoas possam interagir, compreender e dar manutenção aos códigos do programa. Com o objetivo de analisar o trabalho desenvolvido, aplicou-se uma ferramenta para avaliar a qualidade da solução e extrair estatísticas técnicas do sistema. Na tabela 3 apresentam-se os dados quantitativos.

\begin{tabular}{l|c}
\hline Indicador técnico & Quantidade \\
\hline Total de linhas de código & 4.376 \\
\hline Total de classes & 107 \\
\hline Total de pacotes & 27 \\
\hline Total de pacotes de bibliotecas externas & 51 \\
\hline Total de classes pertencentes a bibliotecas externas utilizadas & 142 \\
\hline
\end{tabular}

Tabela 3: Estatísticas técnicas.

Fonte: Martins et al. (2021).

A Tabela 3 apresenta estatísticas técnicas extraídas a partir do código fonte do software. O processo de análise das métricas, e também da qualidade do código desenvolvido, é provido pela ferramenta CodeMR. Através dessa aplicação é possível gerar métricas de complexidade, coesão, acoplamento e tamanho de código. 
(A) Complexidade

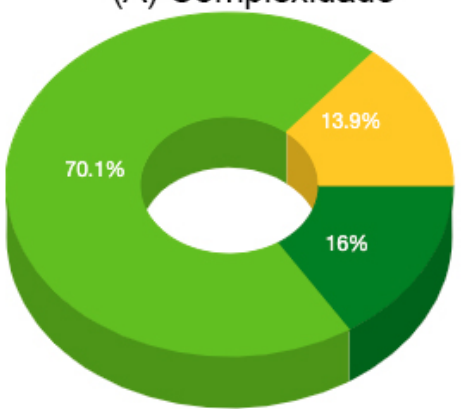

(C) Linhas de código

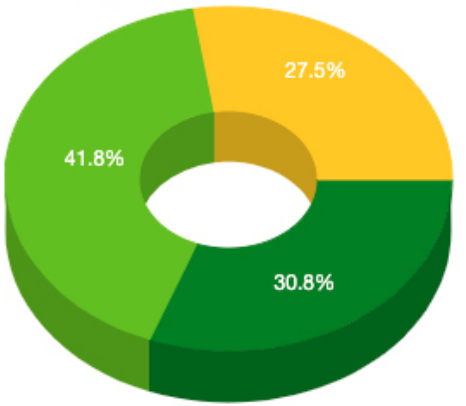

(B) Tamanho

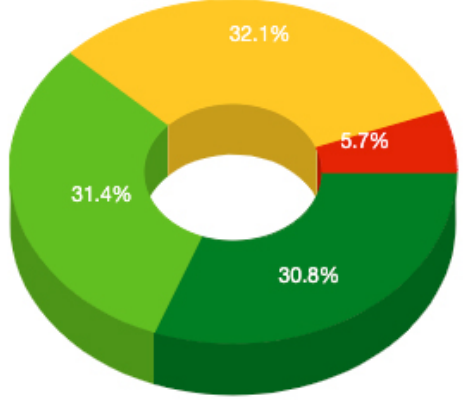

(D) Falta de coesão

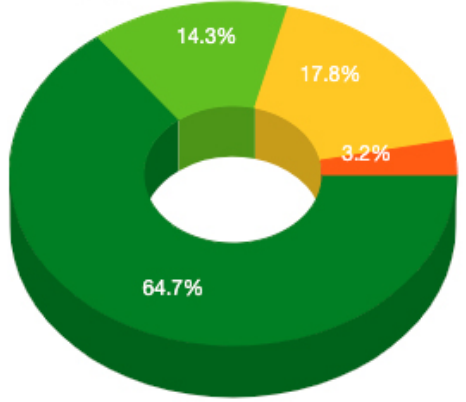

Altíssimo

Alto

Médio

Baixo

Baixíssimo

Figura 4: Estatísticas de qualidade de código.

Fonte: Martins et al. (2021).

Na Figura 4 constam alguns gráficos que evidenciam a qualidade do programa desenvolvido. Observa-se que o código possui uma complexidade baixa (seção A), sendo $70 \%$ classificado como baixo, e $13 \%$, como médio. O fato de o programa ter baixa complexidade não significa que ele possua uma lógica simples ou que represente um programa pequeno. Pelo contrário, ele foi organizado e estruturado de modo que estruturas complexas pudessem ser divididas em unidades menores, facilitando o desenvolvimento e manutenção.

Quanto ao tamanho (seção B), o gráfico classifica o quão grandes são os arquivos que compõem a aplicação, e para esse fim considera-se o total de linhas e quantidade ações que são desenvolvidas em cada arquivo. De modo geral, quanto mais tarefas são feitas pelo mesmo item, maiores são as chances de ele estar mal dimensionado. Nesse caso, em específico, são duas classes que são classificadas com alto peso, trata-se das unidades responsáveis por realizar a importação do arquivo CSV, portanto, é aceitável essa classificação dada as diversas circunstâncias que são processadas ao importar os dados.

No que diz respeito à quantidade de linhas (seção C), o sistema apresenta um desempenho bom. Nota-se que todas as classes estão classificadas de médio a baixo, isso ocorre principalmente pelos padrões arquiteturais adotados, os quais distribuem as 
lógicas em diferentes estruturas, logo, reduzem as linhas de código por arquivo e, em consequência, aumentam o poder de reuso de código.

Por fim, o indicador de falta de coesão (seção D) aponta a maturidade do código. Apenas uma classe é classificada não coesa, o que significa que apenas um item foi classificado como "confuso". Esse indicador utiliza uma complexa lógica para determinar o estado do arquivo, para isso considera-se o total de linhas, ações e atributos, além de analisar como são utilizados os recursos do arquivo. No geral, a aplicação apresenta excelentes métricas do ponto de vista técnico, e um desempenho adequado, portanto, acredita-se que o produto Elum, além de informativo, é uma solução robusta e eficiente.

\section{Resultados}

O aplicativo foi desenvolvido a partir da ideia das perguntas frequentes frequently asked questions - FAQ. A intenção pelo viés da comunicação foi transformar o software criado em uma ferramenta de "autoatendimento".

A busca por um "efeito" de comunicação foi construída a partir da articulação entre a comunicabilidade dos indicadores e um possível posicionamento do usuário/cidadão. Desta forma, a ênfase na exposição dos indicadores está nas perguntas e não na apresentação pontual de cada indicador.

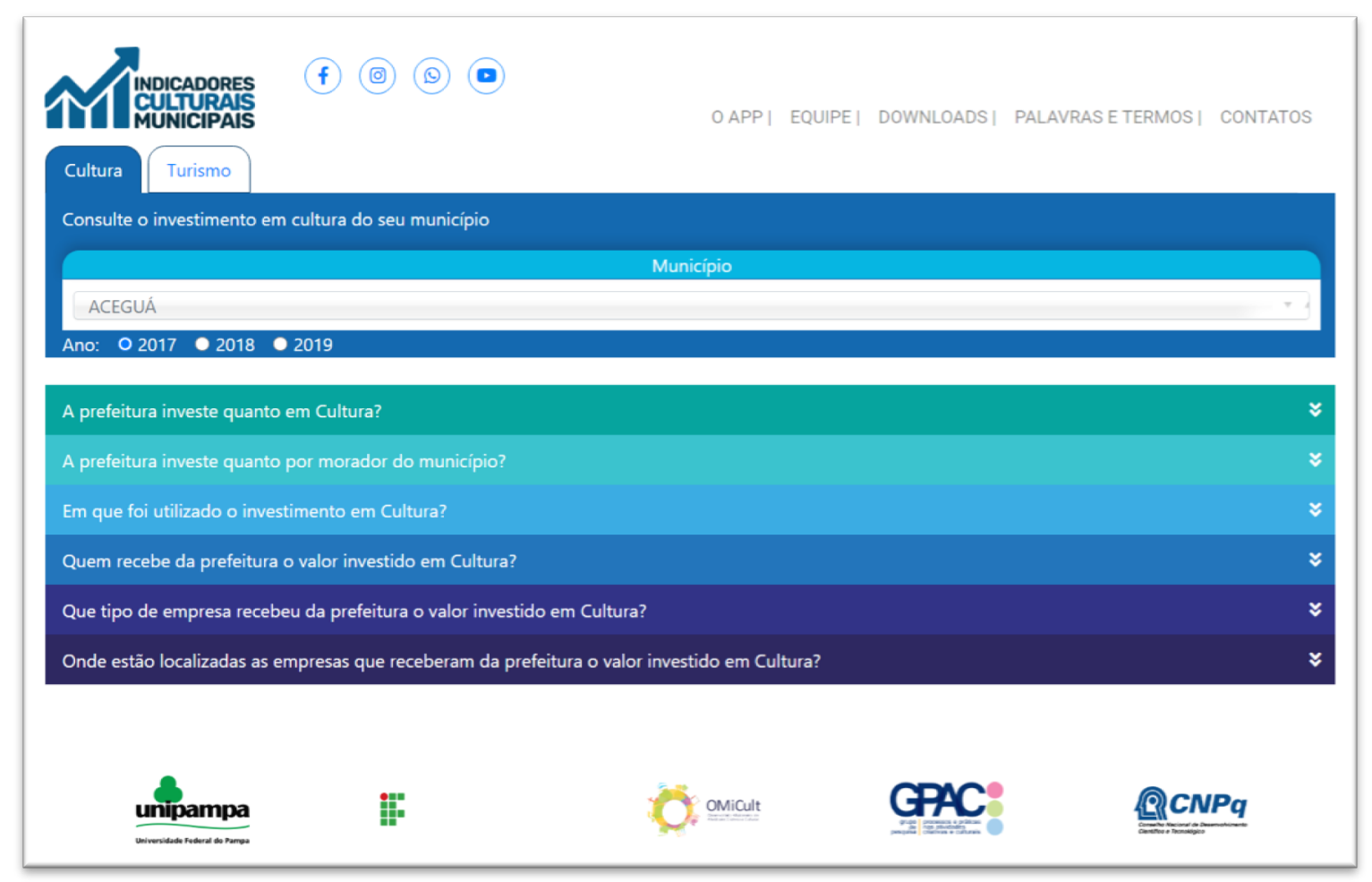

Figura 5: Aplicativo Elum - disposição das perguntas.

Fonte: Martins et al. (2021). 
Recursos como o uso de imagens, ícones e botões de acesso complementar às informações também foram utilizados no aplicativo. Cada pergunta e resposta, ou seja, cada indicador possui uma cor de identificação. A proposta foi deixar o aplicativo visualmente agradável e com possibilidade de interação para a busca por reflexão e ação sobre o que ele sintetiza. As Figuras 6 e 7 destacam alguns artifícios utilizados.

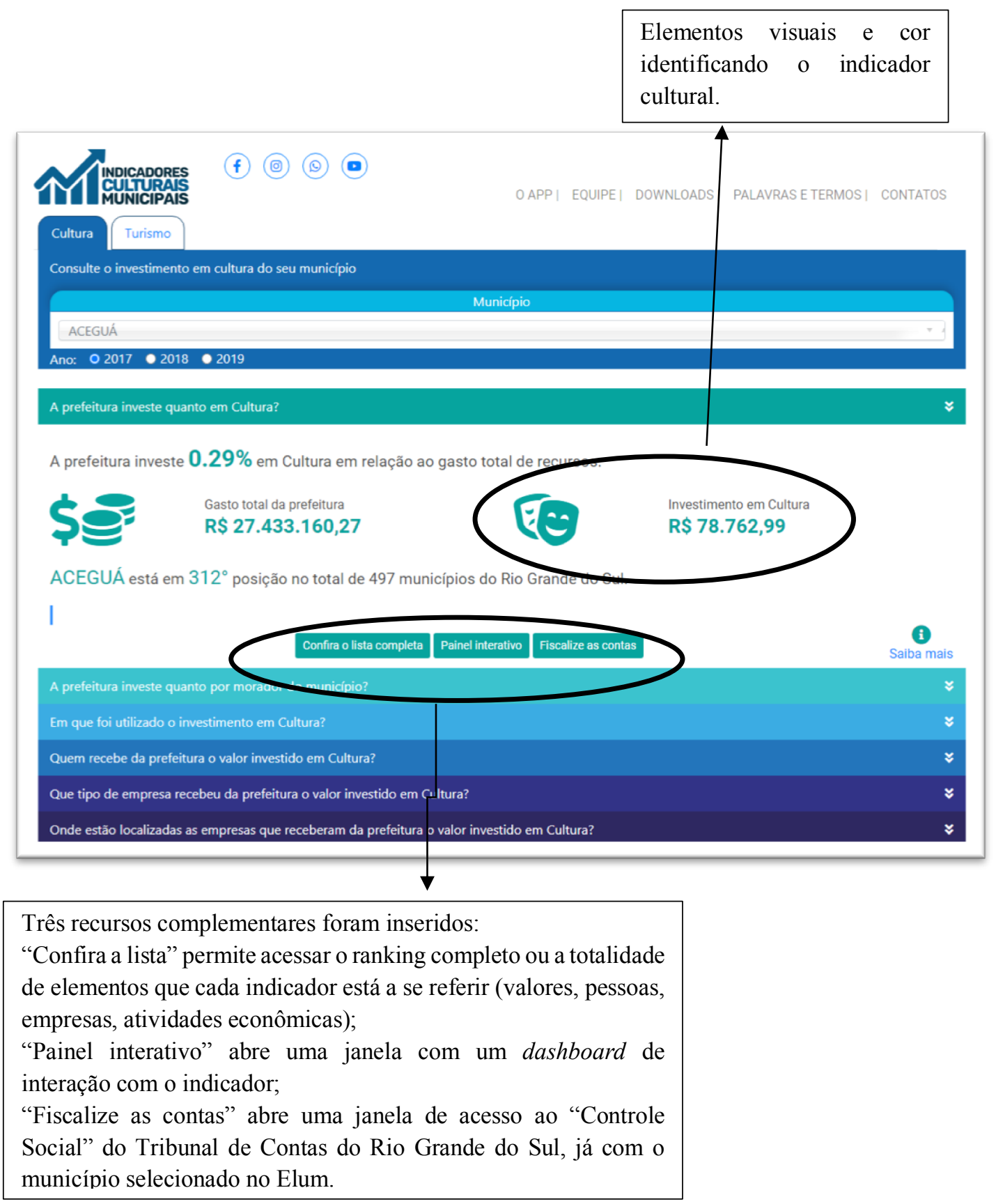

Figura 6: Aplicativo Elum.

Fonte: Martins et al. (2021). 


\section{Elum}

\begin{tabular}{|c|c|}
\hline \multicolumn{2}{|r|}{ Ficha do indicador } \\
\hline $\begin{array}{l}0 \text { que se quer } \\
\text { saber? }\end{array}$ & O percentual (\%) de investimento em Cultura em relação ao gasto total da prefeitura. \\
\hline O indicador $\hat{E}$ & $\begin{array}{l}\text { Um valor numérico que representa os recursos financeiros utilizados para fomentar a } \\
\text { Cultura em relação a todos os gastos da prefeitura em um determinado ano. }\end{array}$ \\
\hline $\begin{array}{l}O \text { indicador } \\
\text { NÃOÉ }\end{array}$ & $\begin{array}{l}\text { Resultado de uma pesquisa específica feita com uma parte das informações das } \\
\text { prefeituras; } \\
\text { Um produto criado por uma prefeitura; } \\
\text { Um conjunto de informações já analisadas pelo Tribunal de Contas para fiscalizar as } \\
\text { contas das prefeituras. }\end{array}$ \\
\hline $\begin{array}{l}0 \text { indicador } \\
\text { FAZ }\end{array}$ & $\begin{array}{l}\text { A transformação dos dados em uma representação visual que permite uma } \\
\text { compreensão mais fácil; } \\
\text { A comparação de investimento em Cultura entre as prefeituras do RS. }\end{array}$ \\
\hline $\begin{array}{l}\text { O indicador } \\
\text { NÃO FAZ }\end{array}$ & $\begin{array}{l}\text { A especificação de quais os setores da Cultura recebem investimento; } \\
\text { Uma análise do que foi classificado e investido como Cultura pela prefeitura. }\end{array}$ \\
\hline $\begin{array}{l}\text { Unidade de } \\
\text { medida }\end{array}$ & Percentual (\%) \\
\hline Fórmula & (Investimento Cultura prefeitura $(\mathrm{R} \$) \times 100)$ / Despesa total prefeitura (R\$) \\
\hline Periodicidade & Anual \\
\hline Espacialidade & Municípios \\
\hline $\begin{array}{l}\text { Fonte de } \\
\text { dados }\end{array}$ & Tribunal de contas do Estado do Rio Grande o Sul \\
\hline Importante & $\begin{array}{l}\text { O indicador utiliza os dados da "Função } 13 \text { - Cultura" e da "Subfunção } 695 \text { - Turismo" } \\
\text { dentro do orçamento das prefeituras. Portanto, o que é cultura e turismo para cada } \\
\text { prefeitura dependerá da forma como ela vai aplicar os recursos públicos nesses } \\
\text { setores. Para saber mais, consulte "PALAVRAS E TERMOS". . }\end{array}$ \\
\hline
\end{tabular}

\section{Baixar os dados}

Figura 7: Aplicativo Elum (detalhamento modelo "ficha do indicador").

Fonte: Martins et al. (2021).

\section{Considerações finais}

No que diz respeito aos temas que articulam a pesquisa em tela, nomeadamente cultura, políticas públicas, controle social e comunicação pública, há muito o que fazer para disponibilizar aos setores envolvidos uma ferramenta de observação da realidade cultural que permita a elaboração de informação útil, a constituição de indicadores e, por fim, a reflexão e ação. 
Dos elementos do debate teórico para o desafio de operacionalizar a comunicação pública através da configuração de seis indicadores culturais, nesta pesquisa desenvolveu-se um algoritmo associado a um software: O Elum. Aqui, a visão de uma ciência propositiva se associa aos recursos tecnológicos que criam algoritmos e modelam aplicações com diversas funcionalidades. Quando um algoritmo é constituído para tratar dados das despesas públicas de uma prefeitura e projetar indicadores para o controle social de determinada política, ele operacionaliza a comunicação pública dentro de um "sistema sociotécnico" político. Os dados acessados pela pesquisa foram tratados (enquanto indicadores) e comunicados (enquanto comunicação pública) para gerar uma equivalência cognitiva entre quem os dispõe e quem tem potencial interesse em compreendê-los.

Por fim, vale dizer, a área da comunicação precisa articular-se cada vez mais com outros campos de saber, entre os quais os sistemas de informação. Isso tem implicações epistemológicas para a construção do saber da comunicação diante de algoritmos e interfaces; e metodológicas para a realização de metodologias que possam pensar e desenvolver constructos, modelos e instanciações capazes de gerar soluções para problemas estabelecidos na realidade social.

\section{Agradecimento}

Os autores agradecem ao Conselho Nacional de Desenvolvimento Científico e Tecnológico (CNPq) pela subvenção ao projeto de pesquisa (processo: 425620/2016-6) e pela concessão de bolsa produtividade em pesquisa (306958/2019-8).

\section{Referências}

DUXBURY, N. (2005). Cultural Indicators and Benchmarks in Community Indicator Projects. In: ANDREW, Caroline et al. (Org.). Accounting for Culture: thinking through cultural citizenship. Ottawa: Ottawa Press, 257-272.

FUKUDA PARR, S. (2000). En busca de indicadores de cultura y desarrollo: avances y propuestas. In: UNESCO. Informe Mundial sobre la cultura 2000-2001. Paris: UNESCO, 278-283.

KRUG, S. (2006). Não me faça pensar!: uma abordagem de bom senso à usabilidade na web. Alta Books.

LEMOS, A. (2020). Epistemologia da comunicação, neomaterialismo e cultura digital. Galaxia, São Paulo, 43, 54-66. http://dx.doi.org/10.1590/1982-25532020143970. 
MATOS, H. (2009). Comunicação pública, esfera pública e capital social. In: DUARTE, J. (Org.). Comunicação pública: Estado, mercado, sociedade e interesse público. São Paulo: Atlas, p. 47-58.

MARTINS, T. C., \& PINTO, M. A. (2019). Indicadores culturais, accountability e envolvimento. In: MARTINS, T. C; PINTO, M. A.; SILVA, A. M. (Orgs.). Indicadores culturais no Brasil e em Portugal: subsídios para a comunicação entre Estado e Sociedade. Coleção: icultura\&media n. 5. Porto: FLUP/UPORTO, 19-37.

MENDES, R. (2010). Java Web Start. Java magazine, Grajaú, 82, 36-43.

OBE, R. O, \& HSU, L. S. (2017). PostgreSQL: Up and Running: a Practical Guide to the Advanced Open Source Database. Sebastopol, Califórnia: O'Reilly Media.

REDDEN, G. (2015). Culture, Value and Commensuration: the knowledge Politics of Indicators. In: MACDOWALL, L. et al. (Org.). Making culture count: the politics of cultural measurement. Melbourne: Palgrave Macmillan, 27-41.

SILVA, F. C. C. (2002). Controle social: reformando a administração para a sociedade. O\&S, 24(9), 115-137. 


\section{arevisto Observatório}

ABSTRACT:

This article presentes the result of the research on the articulation between indicators, cultural policies, public communication and the allocation of resources carried out by the municipal public administrations in Rio Grande do Sul (Brasil). In the study, the vision of a propositional science is associated with technological resources that create algorithms and model applications with different functionalities. An algorithm associated with a software was developed: Elum. Therefore, it is reported the research trajectory - in which the accessed data were treated (as indicators) and communicated (as public communication) in intention to generate a cognitive equivalence between those who have them and those who have a potential interest in understanding them.

KEYWORDS: Information systems; Cultural policy; Public administration.

\section{RESUMEN:}

Este artículo presenta el resultado de investigación sobre la articulación entre indicadores, políticas culturales, comunicación pública y asignación de recursos realizada por las administraciones públicas municipales en Rio Grande do Sul (Brasil). En el estudio, la visión de una ciencia proposicional se asocia a recursos tecnológicos que crean algoritmos $y$ modelan aplicaciones con diferentes funcionalidades. Se desarrolló un algoritmo asociado con el software: el Elum. Así, se reporta la trayectoria de investigación en la que los datos accedidos fueron tratados (como indicadores) y comunicados (como comunicación pública) en la búsqueda de generar una equivalencia cognitiva entre quién los tiene y quién tiene un potencial interés en comprenderlos.

PALABRAS-CLAVES: Sistemas de información; Política cultural; Administración pública. 